\title{
An Exploration of Trends in Patient Health Data Safety Concerns: Does Heterogeneity Matter?
}

\author{
Surma Mukhopadhyay, Ph.D. \\ College of Business and Economics \\ Longwood University, US \\ mukhopadhyays@longwood.edu
}

\author{
Ramsankar Basak, Ph.D.* \\ School of Medicine \\ University of North Carolina at \\ Chapel Hill, US \\ rams@email.unc.edu
}

\author{
Brian J. Reithel, Ph.D. \\ School of Business \\ University of Mississippi, US \\ breithel@bus.olemiss.edu
}

\begin{abstract}
There have been ongoing discussions on threats to patients' electronic health information/records (EHR). This study aims to examine the 1) trend in electronic data safeguard concerns and 2) factors associated with such perceptions. Using the Health Information National Trends Survey (HINTS) data from 2014, 2017, and 2018, the study analyzed 7527 patients (representing approximately, 175 million US adult subjects) for their perceptions of information safeguard and withholding information from providers due to privacy/security. About 24\%, 24\%, and $15 \%$ of respondents reported not confident about data safeguard in 2014, 2017, and 2018, respectively. A large population is not firmly confident about data safety and many would withhold information. Although there is a significant trend in improvement of safeguard concerns, there is patient characteristics-related heterogeneity and there are communication quality effects on adverse outcomes of privacy/security concerns. The results will be useful for improving patient utilization of EHRs benefitting patients or healthcare systems.
\end{abstract}

\section{Introduction}

Advancements in network communication and computer technology have brought enormous changes in many industries including healthcare one major transformation that the healthcare industry faced is shifting from maintaining paper-based medical records to electronic medical records. With time, the nature and attributes of the electronic medical record systems have changed. While at the beginning, mainly the providers started using it extensively, in the last few years, the availability of electronic health information (other terminologies such as online medical records (OMR), electronic health records (EHR), personal health records (PHR) are often used to describe the same or similar systems) to the patients has increased significantly [1].

During the earlier adoption stage of OMR, a big concern was the privacy and security of medical records. Very importantly, this issue is still of high importance, which has been reflected in various research studies and other publications over the years. Westin [21] conducted a survey just after the then President, George W. Bush, declared a proposal on electronic healthcare systems in the US and found $70 \%$ of the respondents were concerned about data security. In 2007, Chhanabhai et al. [7] found 73.3\% respondents were concerned about the security and privacy of their medical records stored and managed by electronic systems. Interestingly, when respondents were informed about various available security systems, $80 \%$ of them believed that if implemented, the electronic systems would be more secure. This study was conducted in 2007 and obviously, $62.6 \%$ respondents were not very aware of the electronic systems. Over the past couple of years, patients became more aware of the electronic platforms and as a result, an increase in adoption of online medical record systems has been observed. For example, in a study by Ford et al. [9], it was projected that PHR adoption will exceed $75 \%$ by 2020. Comparatively recently published articles also reflect patient concerns about the privacy and security of online medical records. For example, Vodicka et al. [20] found patient concerns about privacy and security in both phases - pre-adoption and post-adoption. Kenny et al. [13] explained the privacy and security concerns of patients about online medical records and examined antecedents of patient concerns about health information privacy. While there are heightened discussions or incidences of data breach recently, there is an increase in awareness of cyber threats in recent years, including enhanced security protocols enacted by some organizations. Although security/privacy concerns were examined previously, the trajectory of patient concerns (i.e., privacy/security and information disclosure) related

* Corresponding author 
to health data and factors affecting patient concerns/outcomes amidst rapidly evolving scenarios (e.g., growth in mobile users, shrinking gaps of access to the Internet), remain understudied.

\section{Research Questions}

This study asks two questions. 1) Is there a discernible trend in data safety concerns among patients regarding the use of health information electronically? 2) What are the factors that are associated with such perceptions on safety or predict outcomes of safety concerns? This study makes several contributions. To the best of our knowledge, this is the first to provide trends (i.e., evolution of perceptions) on security and privacy perceptions using real word patients with diverse characteristics in a changing environment (e.g., increase in mobile applications, data-related concerns). As such, the information generated in this study makes novel contributions and will be useful in several ways. First, given the relationship between privacy and security and technology adoption, the insight should be useful in forecasting future adoption. Our heterogeneity-driven analysis is novel and will be useful for healthcare intervention suitably tailored to patient subgroups, patient-directed educational efforts, or understanding needs for design purposes. Finally, we generate insight on a unique downstream effect related to privacy/security leading to information withholding. An understanding of the relationship between care provider communication quality and concerns about privacy and security is novel when compared to prior work. Most importantly, such a relationship is modifiable and a potential source of mitigation of adverse outcomes of privacy/security concerns; thus, insights from this work may help devise ways to improve health outcomes.

\section{Literature Review}

The adoption of health information systems helps patients realize many benefits if both providers and patients are confident in assuring the privacy and integrity of information.[4; 14] For this study, we intend to conceptualize health information systems in a conceptually broad manner without minutely differentiating between individual characteristics, if any, of each type such as EHR, OMR, etc. This is so because our focus is on patient privacy/security or safeguard perceptions, not the system itself, as well as to be able to borrow from past studies, which were conducted with a type of systems (e.g., at the time of Angst 2006, mHealth did not exist). Prior work devoted attention significantly to understanding privacy and security concerns [6] but less on its trends. In the early years of EHR, research often focused on comparing the privacy and security of EHR against paper records when many patients were not familiar with EHR as physician practices were still adopting EHR.[3] It is well known that privacy/security concerns negatively affect the use of EHR [5;16]. Thus, health information privacy/security or data safeguard concerns must be understood. With an increase in security breaches on physician practices or health organizations [2], developers have also strengthened systems' security protocols. For example, many healthcare organizations now require additional steps for access (multi-factor authentication). Thus, the impact of such competing forces is not known but such opposing forces should affect patient perceptions.

Past studies found the impact of different demographic factors (e.g., gender or age in Laric et al. [15]). Patients are no longer a homogeneous group. The Institute of Medicine (IOM) and many other stakeholders such as the Agency for Healthcare Research and Quality (AHRQ) have been pushing for insights that are generalizable to and effective in realworld scenarios. For example, minority patients and those who are socioeconomically disadvantaged are "hard to reach" and understudied in current literature. Therefore, understanding heterogeneity is important. Such an approach is geared to produce evidence to make health care safer, higher quality, and accessible.

Due to uncertainty about the privacy and security of their health information, patients may not fully disclose information. Patel et al. [18] reported 12\% patients withheld information from care providers. As such, approaches may prevent patients from fully benefitting from their interaction with providers or utilizing help from other sources. For example, concerned individuals who choose to not discuss with providers may not become knowledgeable and not undertake appropriate health behaviors (e.g., screening for diseases). A study found those who knew about the role of family history or genes in reducing the risk of cancer were more likely to have searched for cancer information.[12] Provider-patient communication and relationship quality improved cancer screening behaviors among adults aged 50 years and older.[19] Thus, understanding the pathways by which privacy and security may potentially harm, prevent help-seeking, or impact optimal health outcomes is very important but has not been studied much. In conclusion, we offer the following hypotheses.

Hypotheses 
1. Concerns about data safety among patients have changed over the years

2.Safety concerns are associated with demography

3. Patient-physician communication positively affects adverse outcomes related to data safety concerns (regarding information withholding).

\section{Data \& Methodology}

Data came from multiple iterations of Health Information National Trends Survey (HINTS) [10], a National Cancer Institute (NCI)-sponsored selfadministered survey, which is part of federally funded surveillance systems. It is an ongoing annual cross-sectional nationally representative survey of non-institutionalized U.S. adults that tracks access to and use of health information and the Internet and health-related knowledge, attitudes, needs, and behaviors. [10] The latest 3 cycles of HINTS data that were available in the summer of 2019 were utilized. Specifically, HINTS 4 cycle 4, HINTS 5 Cycle 1, HINTS 5 cycle 2 surveys that were administered in 2014, 2017, and 2018, respectively were used for this study. These surveys were a single-mode mail survey of individuals living in the United States using a two-stage sampling design. The three iterations that were used had asked about perceptions information safeguard, electronic medical/health records (EHR) use, privacy and security concerns. As the focus of the study was to examine health data safety/safeguard concerns related to electronic health information systems, subjects who used the Internet, or have a smart phone or tablet were included. In addition, patients who were $\geq 18$ years and had a physician visit in recent years $(\leq 2$ years) were considered. Such restrictions improve the validity and relevance of this work.

\section{Measurement of Variables}

Generally, the HINTS survey instrument administered annually includes validated measures. Items are selected from past surveys while new items are developed from relevant theories or literature (e.g., health communication) and undergo extensive pretesting and expert reviews [17]. Careful attention is paid to methodological rigors and comparability of items with other established national health surveys (e.g., National Health Interview Survey).

\section{Dependent variable}

Data safety concerns were measured by two items to be analyzed separately. 1) How confident are you that safeguards (including the use of technology) are in place to protect your medical records from being seen by people who are not permitted to see them? 2) Have you ever kept information from your health care provider because you were concerned about the privacy or security of your medical record? The response options for the first item were 'very confident', 'somewhat confident', and 'not confident'. The second item was a binary variable.

\section{Independent variables}

Time trend is one of the focal objectives. Thus, the year survey was administered was used to examine trends. Year was treated as a categorical variable with 2014 as the reference point.

Two indicators of communication were used to assess healthcare quality. Of those reporting to have gone to a healthcare professional during the past 12 months, subjects were asked: how often did doctors, nurses, or other health professionals (a) give the attention you needed to your feelings and emotions; (b) help you deal with feelings of uncertainty about your health or health care. Respondents rated communication measures on a 4-point scale, including always, usually, sometimes, and never. For the analysis purpose, a higher score implied lesser/poorer quality (e.g., a response of 4 meaning feelings and emotion never addressed).

Frequency of visits to in the recent past: This was a single item 6-point scale. In the last 12 months, excluding times when one went to an emergency room, how many times did one go to a doctor, nurse, or other healthcare professionals to get medical care for oneself? Zero through four means the respective numbers of visits and 5=5-9 visits, and 6 meaning $\geq 10$ visits.

In addition, demography related variables (age, race/ethnicity, education, gender, and censusdesignated area of residence), disease-related variables (e.g., presence of a chronic disease such as diabetes, heart diseases, or cancer, etc.), health information systems use related variables (e.g., accessing medical records) were measured to describe respondents' profile or investigate heterogeneity among patient subgroups.

\section{Statistical Analysis}

HINTS data come with sampling weights. Analysis of HINTS data needs to adjust for complex sampling design and clustering and nonresponse and noncoverage biases of responses; such an approach is necessary to ensure estimation of correct standard errors that are needed for making a valid statistical inference (see HINTS 5 Cycle 1 Methodology Report for calculation of sample weights and replicate 
Table 1: Demographic Attributes of the Study Subjects

\begin{tabular}{|c|c|c|c|c|c|c|}
\hline \multirow[t]{2}{*}{ Attribute } & \multicolumn{2}{|c|}{2014} & \multicolumn{2}{|c|}{2017} & \multicolumn{2}{|c|}{2018} \\
\hline & $\mathrm{N}(\%)$ & $\begin{array}{l}\text { Population- } \\
\text { weighted \% }\end{array}$ & $\mathrm{N}(\%)$ & $\begin{array}{l}\text { Population- } \\
\text { weighted \% }\end{array}$ & $\mathrm{N}(\%)$ & $\begin{array}{l}\text { Population- } \\
\text { weighted } \%\end{array}$ \\
\hline Male & $1001(40)$ & 48.2 & $925(40)$ & 45.7 & $1072(40)$ & 46.2 \\
\hline \multicolumn{7}{|l|}{ Education } \\
\hline Less than high school & $132(5)$ & 8.1 & $90(4)$ & 6.5 & $129(5)$ & 6.1 \\
\hline High school & $393(16)$ & 16.3 & $375(16)$ & 20.8 & $420(16)$ & 20.0 \\
\hline Some college & $811(32)$ & 30.9 & $696(30)$ & 33.1 & $816(31)$ & 41.1 \\
\hline Bachelor's & $724(29)$ & 28.8 & $664(29)$ & 24.0 & 777 (29) & 20.0 \\
\hline Post-Bachelor & $472(19)$ & 15.9 & $491(21)$ & 15.6 & $527(20)$ & 12.8 \\
\hline \multicolumn{7}{|l|}{ Race/ethnicity } \\
\hline White & $1570(62)$ & 67.1 & $1426(64)$ & 65.8 & $1707(64)$ & 65.0 \\
\hline African-American & $404(16)$ & 12.9 & $301(14)$ & 10.6 & $376(14)$ & 11.0 \\
\hline Hispanic & $380(15)$ & 13.6 & $305(14)$ & 15.6 & $361(14)$ & 15.5 \\
\hline Asian & $88(3)$ & 3.9 & $99(4)$ & 5.5 & $122(5)$ & 5.6 \\
\hline Other & $90(4)$ & 2.4 & $80(4)$ & 2.4 & $103(4)$ & 2.8 \\
\hline \multicolumn{7}{|l|}{ Residence } \\
\hline Rural & $89(4)$ & 3.7 & $93(4)$ & 4.6 & $87(3)$ & 3.1 \\
\hline Nonmetro & $204(8)$ & 10.0 & $204(9)$ & 8.7 & $257(10)$ & 9.0 \\
\hline Metro \& nearby & $2239(88)$ & 86.4 & $2029(87)$ & 86.6 & $2325(87)$ & 87.9 \\
\hline Have a Tablet & $1353(54)$ & 57.8 & $1592(69)$ & 70.5 & $1709(65)$ & 64.6 \\
\hline Have a SmartPhone & $1711(68)$ & 75.4 & $1959(84)$ & 88.0 & $2245(85)$ & 88.7 \\
\hline Accessed EHR & $877(35)$ & 35.6 & $920(40)$ & 37.3 & $1691(63)$ & 62.0 \\
\hline Chronic disease (CVD) & $1349(53)$ & 43.7 & $1310(57)$ & 50.2 & $1531(57)$ & 47.1 \\
\hline \multicolumn{7}{|l|}{ No. of CVD } \\
\hline 1 & $757(30)$ & 25.4 & $754(32)$ & 30.4 & $867(32)$ & 28.1 \\
\hline 2 & $403(16)$ & 12.8 & $399(17)$ & 14.4 & $473(18)$ & 14.2 \\
\hline 3 & $114(5)$ & 2.9 & $113(5)$ & 3.3 & $142(5)$ & 3.2 \\
\hline 4 & $33(1)$ & 0.8 & $36(2)$ & 1.5 & $37(1)$ & 1.0 \\
\hline Cancer survivors & $372(15)$ & 8.7 & $355(15)$ & 8.6 & $458(17)$ & 9.6 \\
\hline $\begin{array}{l}\text { Very confident of data } \\
\text { safeguard }\end{array}$ & $528(21)$ & 20.3 & $501(22)$ & 23.5 & $898(34)$ & 34.8 \\
\hline Withheld information & $383(15)$ & 15.1 & $200(9)$ & 10.1 & $234(9)$ & 8.9 \\
\hline
\end{tabular}

Weight calibrated to US population count

EHR: electronic health records; CVD: cardiac, metabolic, or vascular diseases 
Table 2: Trends of Data Security/Safeguard Perception among Different Patient Groups

\begin{tabular}{|c|c|c|c|c|c|c|c|c|c|c|c|c|c|}
\hline \multirow[t]{2}{*}{$\begin{array}{l}\text { Patient } \\
\text { Group }\end{array}$} & \multirow[t]{2}{*}{ Variable } & \multicolumn{3}{|c|}{$\begin{array}{l}\text { Very Confident of } \\
\text { Safeguard vs. not }\end{array}$} & \multicolumn{3}{|c|}{$\begin{array}{l}\text { Somewhat Confident of } \\
\text { Safeguard vs. not }\end{array}$} & \multicolumn{3}{|c|}{$\begin{array}{l}\text { Not Confident of } \\
\text { Safeguard vs. not }\end{array}$} & \multicolumn{3}{|c|}{$\begin{array}{l}\text { Withheld Information for } \\
\text { Security/Privacy vs. not }\end{array}$} \\
\hline & & Parameter & SE & $\begin{array}{l}\text { Odds } \\
\text { ratio }\end{array}$ & Parameter & SE & $\begin{array}{l}\text { Odds } \\
\text { ratio }\end{array}$ & Parameter & SE & $\begin{array}{l}\text { Odds } \\
\text { ratio }\end{array}$ & Parameter & SE & $\begin{array}{c}\text { Odds } \\
\text { ratio }\end{array}$ \\
\hline \multirow[t]{3}{*}{ All } & Intercept & $-1.365 * * *$ & 0.072 & & $0.287 * * *$ & 0.062 & & $-1.235 * * *$ & 0.082 & & $-1.730 * * *$ & 0.083 & \\
\hline & 2017 & $0.185 *$ & 0.104 & 1.204 & -0.106 & 0.086 & 0.900 & -0.033 & 0.104 & 0.968 & $-0.452 * *$ & 0.162 & 0.637 \\
\hline & 2018 & $0.739 * * *$ & 0.107 & 2.093 & $-0.285 * *$ & 0.091 & 0.752 & $-0.492 * * *$ & 0.139 & 0.612 & $-0.596 * * *$ & 0.135 & 0.551 \\
\hline \multirow[t]{3}{*}{$\begin{array}{l}\text { EHR use } \\
\text { experience }\end{array}$} & Intercept & $-1.359 * * *$ & 0.139 & & $0.551 * * *$ & 0.118 & & $-1.650 * * *$ & 0.162 & & $-1.699 * * *$ & 0.146 & \\
\hline & 2017 & $0.452 * *$ & 0.177 & 1.571 & $-0.304 *$ & 0.158 & 0.738 & -0.077 & 0.224 & 0.926 & $-0.470 * *$ & 0.239 & 0.625 \\
\hline & 2018 & $0.744 * * *$ & 0.161 & 2.105 & $-0.605 * * *$ & 0.144 & 0.546 & 0.009 & 0.217 & 1.009 & $-0.669 * * *$ & 0.195 & 0.512 \\
\hline \multicolumn{14}{|l|}{$\begin{array}{l}\text { No EHR } \\
\text { use }\end{array}$} \\
\hline \multirow{2}{*}{ experience } & 2017 & 0 & 0.151 & 1.000 & -0.004 & 0.105 & 0.996 & 0.005 & 0.114 & 1.005 & $-0.442 * *$ & 0.216 & 0.643 \\
\hline & 2018 & $0.723 * * *$ & 0.164 & 2.061 & -0.052 & 0.131 & 0.950 & $-0.838 * * *$ & 0.163 & 0.433 & $-0.514 * *$ & 0.190 & 0.598 \\
\hline \multirow[t]{3}{*}{$\begin{array}{l}\text { Chronic } \\
\text { patients }\end{array}$} & Intercept & $-1.400 * * *$ & 0.098 & & $0.298 * * *$ & 0.078 & & $-1.218 * * *$ & 0.095 & & $-1.811 * * *$ & 0.116 & \\
\hline & 2017 & $0.296 * *$ & 0.136 & 1.345 & -0.15 & 0.116 & 0.861 & -0.082 & 0.137 & 0.921 & -0.282 & 0.238 & 0.754 \\
\hline & 2018 & $0.940 * * *$ & 0.136 & 2.560 & $-0.427 * * *$ & 0.112 & 0.653 & $-0.555 * * *$ & 0.149 & 0.574 & $-0.594 * * *$ & 0.180 & 0.552 \\
\hline \multirow[t]{3}{*}{$\begin{array}{l}\text { Cancer } \\
\text { survivors }\end{array}$} & Intercept & $-1.007 * * *$ & 0.185 & & 0.196 & 0.164 & & $-1.492 * * *$ & 0.169 & & $-2.024 * * *$ & 0.208 & \\
\hline & 2017 & -0.272 & 0.261 & 0.762 & -0.056 & 0.217 & 0.945 & $0.380 *$ & 0.229 & 1.462 & -0.577 & 0.359 & 0.562 \\
\hline & 2018 & $0.784 * * *$ & 0.243 & 2.191 & $-0.511 * *$ & 0.215 & 0.600 & -0.377 & 0.268 & 0.686 & -0.195 & 0.415 & 0.823 \\
\hline
\end{tabular}

$*$, **, ***: represent $\mathrm{P}<0.1, \mathrm{P}<0.05$, and $\mathrm{P} \leq 0.001$, respectively; $\mathrm{SE}$ : standard error; EHR: electronic health records 
weights).[10] Briefly, weights were derived by adjusting for the probability of selecting the household and household nonresponse and finally these initial weights were calibrated to US population counts. Replicate weights were derived by using the delete-one jackknife procedure. We provide unweighted descriptions of study subjects and corresponding population-level proportions with the use of weights as well. In other words, sample weights along with the specification of replicate weights or strata and clusters can be used to aggregate survey responses for computing estimates that represent a population or a segment defined by attributes such as area, demography, or temporality (e.g., state-level or region-specific number of Internet users). For hypothesis testing, we used simple and multivariable logistic regressions. For each of these regression analyses, we accounted for sampling design issues by using weighting methods deemed as appropriate and advised by the HINTS methodology report.

\section{Results and Discussion}

The study included 7527 subjects from all three iterations of data collection (Table 1). The final study sample had respondents representing over 175 million US populations (applying weights provided by the survey sponsor as described above). The average age of the subjects is about 55 years (SD 15.7) with $40 \%$ being male. However, the weighted proportion of male is a slightly higher representing almost an even distribution between male and female (Table 1) and the mean weighted age is slightly lower (about 48 years). Respondents came from a pool of diverse social segments concerning race (e.g., about $63 \%$ White), area of residence (e.g., $4 \%$ from rural areas), education (e.g., 29\% with a bachelor's degree). A total of 4190 subjects (55.8\%) reported having at least one chronic disease such as diabetes, heart problems, high blood pressure, and chronic lung diseases. About 6\% reported having three or more multiple chronic conditions (MCC). A total of 1185 (16\%) reported being cancer survivors.

Table 2 presents trends in data security and safeguard concerns as expressed by subjects/ patients regarding their electronic health information. About 3500 subjects reported having made some sorts of electronic contact or exchanged information electronically (e.g., email, tracking lab results, etc.) with their providers. Patients making such contacts have substantially gone up since 2014. Yet, 597 (24\%), 547 (24\%), and 393 (15\%) respondents reported not being confident about health data safeguard in 2014, 2017, and 2018, respectively (representing corresponding US population proportions of $22.5 \%, 22 \%$, and $15 \%$ ). To analyze data safeguard concerns, initially, ordinal logistic regression modeling was tried. However, because of the proportional odds assumption violation, a series of univariate binary logistic regressions were run (Table 2). The odds of reporting very confident of safeguard increased by $20 \%$ in 2017 and by $100 \%$ in 2018 since 2014. On the contrary, the odds of being not confident (vs. others) significantly decreased only in 2018 compared to 2014. A similar trend is seen when modeled the odds of somewhat confident (vs. either not or very confident). The last group is inherently heterogeneous in that those expressing only partial confidence can upgrade to very confident or worsen to report not confident. The odds of saying somewhat confident compared to very confident decreased significantly (odds ratio [OR] $=0.51$, $\mathrm{P}<0.001$ ) in 2018 but marginally in 2017 (OR=0.83, $\mathrm{P}=0.08)$. However, compared to not confident, the odds of saying somewhat confident marginally increased $(\mathrm{P}=0.06)$ only in 2018 since 2014. Additionally, such trends were further explored in different patient subgroups such as EHR users, EHR nonusers, cancer survivors, etc. Overall, subgroup analysis results were consistent with the ones discussed above. Trends over time potential can have linear and/or quadratic components. Orthogonal polynomial trend contrasts revealed the presence of both components - quadratic trends were more consistently seen - while a mild degree of variation exists across different subgroups. For example, in the cancer survivor group as well as in the EHR nonuser group only quadratic trend was strongly visible, while in EHR users and chronic patients mild linear trends were also present in addition to strong quadratic trends. In addition, in the model that compared somewhat confident against very confident, the quadratic trend was strongly significant $(\mathrm{P}<0.001)$. If this trend continues, a large proportion of currently not firmly confident should uplift to very confident in the near future. Policymakers, providers, and healthcare software makers should closely watch out for areas that keep such a positive momentum on.

Next, we examined factors that are associated with patients' concerns for data safeguard. As above, binary logistic regressions were run in the full cohort as well as in different subgroups to check for any heterogeneity. Table 3 presents regression results on factors associated with reporting very confident about data safeguards. Compared to subjects with less than high school education, each of other higher levels of education is associated with a decrease in odds of feeling very confident. Race has a moderate effect in 
Table 3: Factors Associated with Confidence on Data Safeguard Perception among Different Patient Groups

\begin{tabular}{|c|c|c|c|c|c|c|c|c|c|c|c|c|c|c|c|}
\hline \multirow[t]{2}{*}{ Variable } & \multicolumn{3}{|c|}{ All } & \multicolumn{3}{|c|}{ EHR } & \multicolumn{3}{|c|}{ No EHR } & \multicolumn{3}{|c|}{ CVD } & \multicolumn{3}{|c|}{ Cancer Survivors } \\
\hline & Parameter & SE & $\begin{array}{c}\text { Odds } \\
\text { ratio }\end{array}$ & Parameter & SE & $\begin{array}{c}\text { Odds } \\
\text { ratio }\end{array}$ & Parameter & SE & $\begin{array}{c}\text { Odds } \\
\text { ratio }\end{array}$ & Parameter & SE & $\begin{array}{c}\text { Odds } \\
\text { ratio }\end{array}$ & Parameter & SE & $\begin{array}{l}\text { Odds } \\
\text { ratio }\end{array}$ \\
\hline $\begin{array}{l}\text { Intercept } \\
\text { Year (ref. } \\
\text { 2014) }\end{array}$ & $-0.852 * * *$ & 0.253 & & $-0.863 *$ & 0.503 & & $-0.621 *$ & 0.371 & & $-0.990 * *$ & 0.328 & & -0.199 & 0.761 & \\
\hline 2017 & $0.280 * *$ & 0.115 & 1.323 & $0.393 * *$ & 0.189 & 1.482 & 0.159 & 0.165 & 1.173 & $0.441 * *$ & 0.148 & 1.554 & -0.154 & 0.280 & 0.857 \\
\hline $\begin{array}{l}\quad 2018 \\
\text { Education } \\
\text { (ref. <HS) }\end{array}$ & $0.721 * * *$ & 0.110 & 2.057 & $0.606 * * *$ & 0.178 & 1.833 & $0.716 * * *$ & 0.169 & 2.046 & $0.933 * * *$ & 0.146 & 2.541 & $0.818 * *$ & 0.268 & 2.266 \\
\hline $\begin{array}{l}\text { HS } \\
\text { Some }\end{array}$ & $-0.468 * *$ & 0.223 & 0.626 & -0.68 & 0.486 & 0.507 & -0.356 & 0.278 & 0.700 & $-0.526 * *$ & 0.262 & 0.591 & $-0.901 *$ & 0.526 & 0.406 \\
\hline College & $-0.455 * *$ & 0.212 & 0.634 & -0.649 & 0.439 & 0.523 & -0.424 & 0.272 & 0.654 & $-0.534 * *$ & 0.263 & 0.586 & $-0.815 *$ & 0.484 & 0.442 \\
\hline College & $-0.600 * *$ & 0.229 & 0.549 & -0.719 & 0.466 & 0.487 & $-0.653 * *$ & 0.282 & 0.521 & $-0.599 * *$ & 0.281 & 0.549 & $-1.327 * *$ & 0.484 & 0.265 \\
\hline Professional & $-0.719 * * *$ & 0.219 & 0.487 & $-0.893 *$ & 0.457 & 0.409 & $-0.723 * *$ & 0.301 & 0.486 & $-0.816 * *$ & 0.291 & 0.442 & $-1.125 * *$ & 0.500 & 0.325 \\
\hline $\begin{array}{l}\text { Age } \\
\text { Race (ref. } \\
\text { White) }\end{array}$ & -0.002 & 0.004 & 0.998 & $0.010 *$ & 0.005 & 1.010 & $-0.013 * *$ & 0.006 & 0.987 & 0.001 & 0.005 & 1.001 & -0.002 & 0.011 & 0.998 \\
\hline Black & 0.115 & 0.136 & 1.122 & 0.284 & 0.195 & 1.329 & -0.05 & 0.192 & 0.951 & 0.16 & 0.168 & 1.174 & 0.227 & 0.401 & 1.254 \\
\hline Hispanic & $0.344 * *$ & 0.157 & 1.411 & 0.326 & 0.225 & 1.385 & $0.388 *$ & 0.217 & 1.473 & 0.108 & 0.220 & 1.115 & 0.141 & 0.499 & 1.152 \\
\hline Asian & 0.05 & 0.278 & 1.051 & 0.316 & 0.372 & 1.371 & -0.376 & 0.302 & 0.687 & -0.314 & 0.334 & 0.730 & 0.607 & 0.998 & 1.836 \\
\hline Other & $-0.431 *$ & 0.240 & 0.650 & -0.384 & 0.348 & 0.681 & -0.602 & 0.393 & 0.547 & -0.381 & 0.381 & 0.683 & 0.811 & 0.807 & 2.251 \\
\hline $\begin{array}{l}\text { Male } \\
\text { Residence (ref } \\
\text { metro) }\end{array}$ & -0.071 & 0.090 & 0.931 & -0.035 & 0.106 & 0.965 & -0.121 & 0.147 & 0.886 & -0.05 & 0.118 & 0.952 & 0.034 & 0.230 & 1.035 \\
\hline Rural & 0.022 & 0.234 & 1.022 & 0.195 & 0.316 & 1.215 & -0.016 & 0.316 & 0.984 & -0.084 & 0.321 & 0.919 & -0.187 & 0.588 & 0.830 \\
\hline $\begin{array}{l}\text { Nonmetro } \\
\text { Visit }\end{array}$ & 0.155 & 0.165 & 1.167 & 0.296 & 0.210 & 1.345 & 0.111 & 0.222 & 1.118 & 0.259 & 0.186 & 1.295 & 0.154 & 0.351 & 1.167 \\
\hline Frequency & -0.003 & 0.024 & 0.997 & -0.038 & 0.033 & 0.963 & 0.022 & 0.040 & 1.022 & 0.006 & 0.032 & 1.006 & 0.014 & 0.061 & 1.014 \\
\hline
\end{tabular}

*, **, ***: represent $\mathrm{P}<0.1, \mathrm{P}<0.05$, and $\mathrm{P} \leq 0.001$, respectively; $\mathrm{SE}$ : standard error; HS: high school; EHR: electronic health records; CVD: cardiac, metabolic, or vascular diseases ref: reference group 
Table 4: Factors Associated with Information Withholding for Security/Privacy Concerns among Different Patient Group

\begin{tabular}{|c|c|c|c|c|c|c|c|c|c|c|c|c|c|c|c|}
\hline \multirow[t]{2}{*}{ Variable } & \multicolumn{3}{|c|}{ All } & \multicolumn{3}{|c|}{ EHR } & \multicolumn{3}{|c|}{ No EHR } & \multicolumn{3}{|c|}{ CVD } & \multicolumn{3}{|c|}{ Cancer Survivors } \\
\hline & Parameter & SE & $\begin{array}{l}\text { Odds } \\
\text { ratio }\end{array}$ & Parameter & SE & $\begin{array}{l}\text { Odds } \\
\text { ratio }\end{array}$ & Parameter & SE & $\begin{array}{l}\text { Odds } \\
\text { ratio }\end{array}$ & Parameter & SE & $\begin{array}{l}\text { Odds } \\
\text { ratio }\end{array}$ & Parameter & SE & $\begin{array}{l}\text { Odds } \\
\text { ratio }\end{array}$ \\
\hline Intercept & $-2.517 * * *$ & 0.706 & & $-2.617 * * *$ & 0.731 & & $-2.354 * *$ & 1.119 & & $-2.936 * * *$ & 0.650 & & $\begin{array}{c}-4.976 \\
* * *\end{array}$ & 1.500 & \\
\hline \multicolumn{16}{|l|}{ Year (ref. 2014) } \\
\hline 2017 & $-0.412 * *$ & 0.191 & 0.662 & $-0.455 *$ & 0.275 & 0.634 & -0.386 & 0.274 & 0.680 & -0.3 & 0.262 & 0.741 & -0.083 & 0.443 & 0.921 \\
\hline 2018 & $-0.598 * * *$ & 0.151 & 0.550 & $-0.571 * *$ & 0.204 & 0.565 & $-0.697 * * *$ & 0.212 & 0.498 & $-0.678 * * *$ & 0.212 & 0.508 & 0.347 & 0.515 & 1.415 \\
\hline \multicolumn{16}{|l|}{$\begin{array}{l}\text { Education (ref. } \\
<\mathrm{HS} \text { ) }\end{array}$} \\
\hline HS & -0.313 & 0.464 & 0.731 & -0.422 & 0.700 & 0.656 & -0.293 & 0.648 & 0.746 & 0.138 & 0.464 & 1.148 & 0.692 & 1.546 & 1.997 \\
\hline Some College & -0.325 & 0.446 & 0.723 & -0.48 & 0.631 & 0.619 & -0.227 & 0.654 & 0.797 & 0.516 & 0.414 & 1.675 & 0.272 & 1.463 & 1.313 \\
\hline College & -0.431 & 0.443 & 0.650 & -0.397 & 0.624 & 0.672 & -0.578 & 0.648 & 0.561 & 0.236 & 0.408 & 1.266 & 0.032 & 1.489 & 1.032 \\
\hline Professional & -0.267 & 0.451 & 0.765 & -0.413 & 0.648 & 0.662 & -0.206 & 0.621 & 0.814 & 0.192 & 0.440 & 1.211 & 0.229 & 1.470 & 1.257 \\
\hline Age & $-0.014 * *$ & 0.005 & 0.986 & $-0.009 *$ & 0.005 & 0.992 & $-0.019 * *$ & 0.008 & 0.981 & $-0.028 * * *$ & 0.006 & 0.972 & -0.015 & 0.016 & 0.986 \\
\hline \multicolumn{16}{|l|}{ Race (ref. White) } \\
\hline Black & 0.274 & 0.216 & 1.315 & 0.231 & 0.348 & 1.260 & 0.376 & 0.281 & 1.457 & $0.446 *$ & 0.239 & 1.562 & -0.754 & 0.591 & 0.470 \\
\hline Hispanic & $0.628 * *$ & 0.218 & 1.874 & $0.503 *$ & 0.296 & 1.654 & $0.753 * *$ & 0.316 & 2.124 & 0.413 & 0.342 & 1.512 & $1.373 *$ & 0.766 & 3.946 \\
\hline Asian & 0.421 & 0.312 & 1.524 & 0.497 & 0.422 & 1.644 & 0.455 & 0.473 & 1.576 & $0.914 * *$ & 0.379 & 2.494 & 1.073 & 0.922 & 2.924 \\
\hline Other & 0.255 & 0.361 & 1.291 & -0.21 & 0.517 & 0.811 & 0.532 & 0.535 & 1.702 & 0.498 & 0.459 & 1.645 & -0.296 & 14.089 & 0.744 \\
\hline Male & 0.25 & 0.154 & 1.284 & 0.219 & 0.196 & 1.245 & 0.278 & 0.223 & 1.320 & $0.420 * *$ & 0.205 & 1.523 & -0.028 & 0.406 & 0.972 \\
\hline \multicolumn{16}{|l|}{$\begin{array}{l}\text { Residence (ref } \\
\text { metro) }\end{array}$} \\
\hline Rural & 0.138 & 0.319 & 1.148 & 0.319 & 0.485 & 1.376 & 0.07 & 0.460 & 1.073 & -0.311 & 0.532 & 0.732 & -1.203 & 1.422 & 0.300 \\
\hline Nonmetro & 0.154 & 0.299 & 1.166 & -0.37 & 0.398 & 0.691 & 0.354 & 0.388 & 1.425 & 0.039 & 0.397 & 1.040 & -1.062 & 0.744 & 0.346 \\
\hline Visit Frequency & 0.056 & 0.050 & 1.058 & 0.006 & 0.063 & 1.006 & 0.097 & 0.080 & 1.102 & 0.087 & 0.063 & 1.091 & $0.294 * *$ & 0.125 & 1.342 \\
\hline $\begin{array}{l}\text { Feelings } \\
\text { Addressed }\end{array}$ & $0.243 * *$ & 0.108 & 1.275 & 0.12 & 0.171 & 1.127 & $0.352 * *$ & 0.120 & 1.421 & $0.294 * *$ & 0.136 & 1.342 & $0.536 * *$ & 0.234 & 1.710 \\
\hline $\begin{array}{l}\text { Help with } \\
\text { Uncertainty }\end{array}$ & $0.276 * *$ & 0.105 & 1.318 & $0.530 * * *$ & 0.164 & 1.699 & 0.039 & 0.132 & 1.040 & $0.261 * *$ & 0.127 & 1.298 & 0.299 & 0.263 & 1.348 \\
\hline
\end{tabular}

*, **, ***: represent $\mathrm{P}<0.1, \mathrm{P}<0.05$, and $\mathrm{P} \leq 0.001$, respectively; SE: standard error; HS: high school; EHR: electronic health records; CVD: cardiac, metabolic, or vascular diseases ref: reference group 
that only a few racial groups compared to whites showed significant association (e.g., for Hispanic, $\mathrm{OR}=1.41, \mathrm{P}=0.03)$. In multivariable main effect models, the time trend effects remain strong. There is a modest degree of variation in the effects of some predictors across different subtypes. For example, unlike other subgroups, the effect of education on odds of very confident remained consistent and significant $(\mathrm{P}<0.05)$ in the CVD group and almost seemed to decrease in a linear fashion over any increase in education. In contrast, such effects were not present among patient reporting prior EHR use. We also explored models with interaction terms with time. What is notable is that some of the main effects along with the interactions became significant. For example, in the full cohort, African-Americans reported a significant shift in trends (for interaction effect for 2018, $\mathrm{P}=0.009$ and that of 2017, $\mathrm{P}=0.08$ and both ORs being <1) while the main effect for African-Americans remained positive and significant $(\mathrm{P}=0.02)$. It implies a downward trend in confidence over the years among African-Americans. Thus, the effect of race is more clearly visible in the interaction models. Similarly, for people living in rural areas a significant interaction term $(\mathrm{P}=0.02)$ implies a decrease in confidence in 2018. In addition, interaction effects were visible among subgroup analyses (e.g., with rural folks, significantly decreasing trend among EHR non-user subgroups and marginally decreasing trend among CVD patients). Overall, heterogeneous effects unfold more clearly, if trends are examined together with demographic attributes among different subgroups.

Security and privacy concerns have plagued health care for years. The odds of withholding information from health care providers due to security/privacy concerns of medical records changed over time (Table 1 and Table 4). The ORs of withholding in 2017 and 2018 (0.64 and 0.55, respectively) continued to decrease compared to 2014. The trend demonstrated a strong linear as well as a quadratic trend $(\mathrm{P}<0.01)$. Such trends were prevalent in those who did and did not use EHR previously. However, such trends were not visible in cancer survivors. This is interesting. A cancer diagnosis is extremely unsettling for patients and heightened life-threatening anxiety probably may have overridden other concerns. As such, heterogeneity requires further attention in future studies.

Several factors associated with information withholding were examined (Table 4). Two factors - feelings and emotion addressed by provider and providers helping patients deal with feelings of uncertainty- were strongly negatively associated with withholding information. Prior work found associations between these communication variables and avoidance or delays in care-seeking. [11] Similarly, the current study results imply that these factors are associated with negative health behavior (i.e., withholding information) arising out of data concerns. In other words, if managed properly, these factors are capable of mitigating patient concerns. They were found significant in many subgroups although there was mild heterogeneity in terms of statistical significance of such effects. Among demography-related variables, age affects withholding negatively; that is, with an increase in age the odds of withholding goes down. Patient perceptions of communication in healthcare settings were found to vary widely by demographic attributes and other individual patient characteristics.[8] With increasing age, patients are likely to be reliant on health care or healthcare systems or other concerns take precedence and thus mitigate some of security/privacy concerns. Unlike data safeguard, withholding was not affected by education or was influenced only inconsistently by race. It is interesting to see the effect of race on withholding in the CVD group; especially, some of the effects appear strong (e.g., odds for Asian is 2.5 times that of White). Effective communication between patients and health care providers is a central element of quality-driven care. Such communication that is pivoted to patients' needs and characteristics will help alleviate concerns.

The use of HINTS data in this study constrains this research. The most important limitation is selfreport. Thus, it is not known if patients actually withheld information from their doctors. Or, if they did, to what extent they did so. Other limitations include scale formats (e.g., 3-point, binary, etc.) and single-item measures. Finally, this study is exploratory in nature. Future research should use psychosocial or communication theories to investigate antecedents and outcomes of privacy/security concerns, including the effect of sickness severity on willingness to disclose information or whether or not information nondisclosure is related to only providers, or only to the systems, or both. Yet this study makes important contributions and strengths lie in the use of a nationally representative subject pool and real-world patients needing care for years to come. While it is good to see subjects' concern level decreasing and upswing of positive trends, yet many challenges remain. A substantial size of the population is still a bit skeptic. In particular, there are complex shifts in trends depending on patient attributes. An ideal goal 
is the enhancement of assurance for this group of subjects. Any steps toward increasing assurance will realize the full potential of electronic health information systems. It will enable offering timely and quality-driven care as envisioned by meaningful use goals and empowering patient self-management. Yet another challenge is on part of vendors and developers to keep improving the systems and continue to protect patient sensitive health data.

\section{Conclusion}

Overall, there is a significant trend in the improvement of patients' data safety concerns over the years. Patients are, on average, more confident about data safeguard/safety in recent years than they were a few years before. This is an encouraging finding from the perspective of companies providing or managing health information systems platforms. However, there is a large segment of the population not firmly confident about data safety and many would withhold information from their providers. That there is demography-related heterogeneity and there are communication quality effects on adverse outcomes of safety concerns will be useful for designing any steps intended to mitigate negative patient outcomes, improve patient access to or utilization of electronic health information systems finally benefitting patients or healthcare systems.

\section{References}

[1] American Hospital Association Trend Report (2016). Individuals' ability to electronically access their hospital medical records, perform key tasks is growing. Available at:

https://www.aha.org/system/files/research/reports/tw/16jultw-healthIT.pdf. Accessed April 20, 2018.

[2] American Hospital Association Trend Report (2017). Tackling cybersecurity threat. Available at: https://www.ama-assn.org/sites/default/files/mediabrowser/public/government/advocacy/medicalcybersecurity-findings.pdf. Accessed November10, 2018 [3] Ancker JS, Brenner S, Richardson JE, Silver M, Kaushal R. "Trends in public perceptions of electronic health records during early years of meaningful use". Am $J$ Manag Care. 21.8 (2015):e487-93.

[4] Angst, Corey M. "Protect my privacy or support the common-good? Ethical questions about electronic health information exchanges." Journal of Business Ethics 90.2 (2009): 169-178.

[5] Angst, Corey M., and Ritu Agarwal. "Adoption of electronic health records in the presence of privacy concerns: The elaboration likelihood model and individual persuasion." MIS Quarterly 33.2 (2009): 339-370.
[6] Appari, A., Johnson, ME. "Information security and privacy in healthcare: Current state of research". Int. J. Internet Enterprise Manage. 6,4 (2010), 279-314.

[7] Chhanabhai P, and A Holt, "Consumers are ready to accept the transition to online and electronic records if they can be assured of the security measures." Medscape General Medicine 9.1 (2007): 8.

[8] DeVoe, Jennifer E., Lorraine S. Wallace, and George E. Fryer Jr. "Measuring patients' perceptions of communication with healthcare providers: do differences in demographic and socioeconomic characteristics matter?." Health Expectations 12.1 (2009): 70-80.

[9] Ford, Eric W., Bradford W. Hesse, and Timothy R. Huerta. "Personal health record use in the United States: forecasting future adoption levels." Journal of Medical Internet Research 18.3 (2016): e73.

[10] Health Information National Trends Survey Available at: https://hints.cancer.gov/data/default.aspx. Accessed April 20, 2018.

[11] Kannan, Viji Diane, and Peter J. Veazie. "Predictors of avoiding medical care and reasons for avoidance behavior." Medical Care 52.4 (2014): 336-345.

[12] Kaphingst, Kimberly A., Christina R. Lachance, and Celeste M. Condit. "Beliefs about heritability of cancer and health information seeking and preventive behaviors." Journal of Cancer Education 24.4 (2009): 351-356.

[13] Kenny, Grace, and Regina Connolly. "Drivers of Health Information Privacy Concern: A Comparison Study." Proceedings of the 22nd Americas Conference on Information Systems (AMCIS), 2016: 1-10.

[14] Kotz D, Gunter CA, Kumar S, Weiner JP. "Privacy and security in mobile health: a research agenda". Computer. 49.6(2016):22-30.

[15] Laric, Michael V., Dennis A. Pitta, and Lea Prevel Katsanis. "Consumer concerns for healthcare information privacy: A comparison of US and Canadian perspectives." Research in Healthcare Financial Management 12.1 (2009): 93.

[16] Li, Han, et al. "Examining the decision to use standalone personal health record systems as a trustenabled fair social contract." Decision Support Systems 57 (2014): 376-386.

[17] Nelson, David, et al. "The health information national trends survey (HINTS): development, design, and dissemination." Journal of Health Communication 9.5 (2004): 443-460.

[18] Patel V, Beckjord E, Moser RP, Hughes P, Hesse BW. "The role of health care experience and consumer information efficacy in shaping privacy and security perceptions of medical records: national consumer survey results." JMIR Med Inform 3.2 (2015:):e14.

[19] Underhill, Meghan L., and Marc T. Kiviniemi. "The association of perceived provider-patient communication and relationship quality with colorectal cancer screening." Health Education \& Behavior 39.5 (2012): 555-563.

[20] Vodicka, Elisabeth, et al. "Online access to doctors' notes: patient concerns about privacy." Journal of Medical Internet Research 15.9 (2013): e208.

[21] Westin, Alan F. "Public attitudes toward electronic health records." AHIP Cover 46.4 (2005): 22-25. 